\title{
Optimal Placement of TCSC Based on Sensitivity Analysis for Congestion Management
}

\author{
Naga Raja Kumari $\mathrm{CH}^{\mathbf{1}}$, K. Chendra Sekhar ${ }^{2}$ \\ ${ }^{1}$ Departement of Electrical and Electronics Engineering, Acharya Nagarjuna University, India \\ ${ }^{2}$ Departement of Electrical Engineering, R.V.R \& J.C College of Engineering, India
}

\begin{tabular}{l} 
Article Info \\
\hline Article history: \\
Received Mar 30, 2016 \\
Revised May 21, 2016 \\
Accepted Jun 8, 2016 \\
\hline Keyword: \\
Congestion Management \\
Voltage Stability \\
Rank Corelation \\
Sensitivity Index \\
TCSC
\end{tabular}

Corresponding Author:

Naga Raja Kumari CH

Departement of Electrical and Electronics Engineering

Acharya Nagarjuna University

Nagarjuna Nagar, Guntur, Andhra Pradesh 522510, India

Email: nrkumari84@gmail.com

\begin{abstract}
In a deregulated electricity market whenever congestion management problem occurs, the network collapse because of voltage instability. In this paper total real and reactive power loss deviation based sensitivity indexes (PLDS and QLDS) with rank co-relation concept, has been proposed for the optimal location and operating range of TCSC device. With this placement the power flow in over loaded overhead lines has been reduced and that results in an increased loadability of the power system and also improves the voltage stability and security and also solves the congestion management problem. So ultimately, a more energy efficient transmission system is possible. The case studies were conducted on IEEE 14 bus test system. The ensue corroborate the intended approach for social welfare maximization in real time.
\end{abstract}

Copyright (C) 2016 Institute of Advanced Engineering and Science. All rights reserved.

\section{INTRODUCTION}

In deregulated electricity market due to violation of system operating limits transmission network is unable to accommodate all the desired transactions. In such cases congestion management problems occur and it leads to the occurrence of huge revenue loss to market participants [1]. FACTS technology incorporation in the transmission system will help to capture the unutilised potential of transmission system. Introduction of FACTS devices is an alternative solution to improve the efficiency of existing transmission networks by redispatching line flow patterns in such a way that the thermal limits between grid and stakeholders and increasing the system loadability [2], solves the congestion management problem and also voltage stability problem. Thyristor controlled series capacitor is an important FACTS device which has been used in power system transmission networks [3],[4]. The security of this deregulated power system operation is mainly dependent on the decisions of Independent System Operator (ISO). The optimal decisions under network congestion will maximize social welfare as well as profit of the power system performance.

For this ISO can use the following methods [5]:

1) Cost free methods:

i) Operation of transformers taps/phase shifters

ii) Outing of Congested lines

iii) Operation of FACTS devices particularly Series FACTS devices.

2) Cost based methods:

i) Load curtailment

ii) Rescheduling generation 
Cost free methods have more advantageous than cost based such as without disturbing economic matter. FACTS devices, [6] like Thyristor Controlled Series Capacitor (TCSC) have found to be more useful than other devices. Thyristor Controlled Series Capacitor (TCSC) is a variable impedance type FACTS device and is connected in series with the transmission line to increase the power transfer capability, improve transient stability, and reduce transmission losses [7]. Because of the dynamics TCSC and its contribution to the system study much attractions has been paid on TCSC. In this paper the size and location of FACTS device is chosen based on MTLVS index (minimum transmission loss and maximum voltage stability). With this optimal placement, TCSC contributed for loadability enhancement and so we can avoid for the possibility of congestion in the network and associated economic loss and also voltage instability problems. So a more energy efficient transmission system is possible.

\section{TCSC MODELLING}

According to the IEEE definitions TCSC is a combination of TCR (Thyristor controlled reactor) with a fixed capacitor to enable continuous control over the series compensation. Series capacitive compensation has been used to increase line power transfer as well as to enhance system stability. Figure 1 shows the main circuit of a TCSC.

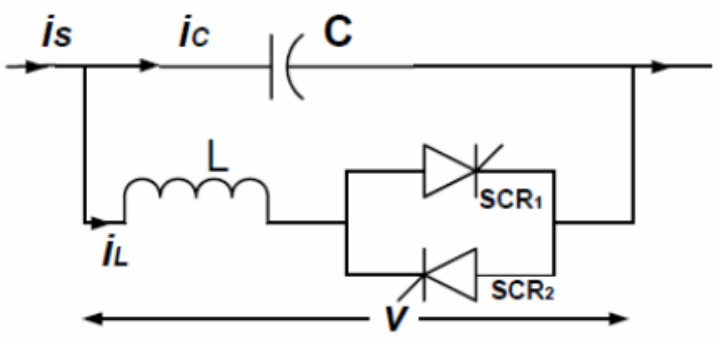

Figure 1. TCSC Configuration

Normally in accordance to the system parameter variations the firing angles of the thyristors are controlled to adjust the TCSC reactance according to the system control algorithm. According to the variation of the thyristor's firing angle, this process can be modelled as a fast switch between corresponding reactance offered to the power system. Avoiding the steady state resonance, TCSC can be operated either in inductive mode or in capacitive mode. There exists a steady-state relationship between the firing angle $\alpha$ and the reactance $X_{T C S C}$.

This relationship can be described by the following equation:

$$
\mathrm{X}_{\mathrm{TCSC}}(\alpha)=\mathrm{X}_{\mathrm{C}} \mathrm{X}_{\mathrm{l}}(\alpha) / \mathrm{X}_{\mathrm{l}}(\alpha)-\mathrm{X}_{\mathrm{C}}
$$

Where,

$$
\mathrm{X}_{1}(\alpha)=\mathrm{X}_{\mathrm{L}}(\pi / \pi-2 \alpha-\sin \alpha)
$$

$\alpha$ is the firing angle, $X_{L}$ is the reactance of the inductor and $X l$ is the effective reactance of the inductor at firing angle. The effective series transmission impedance is given by:

$$
X_{\text {eff }}=(1-k) X
$$

Where $\mathrm{k}$ is the degree of series compensation.

$$
\mathrm{K}=\mathrm{X}_{\mathrm{TCSC}} / \mathrm{X}
$$

Figure 2 shows a transmission line with a TCSC. 


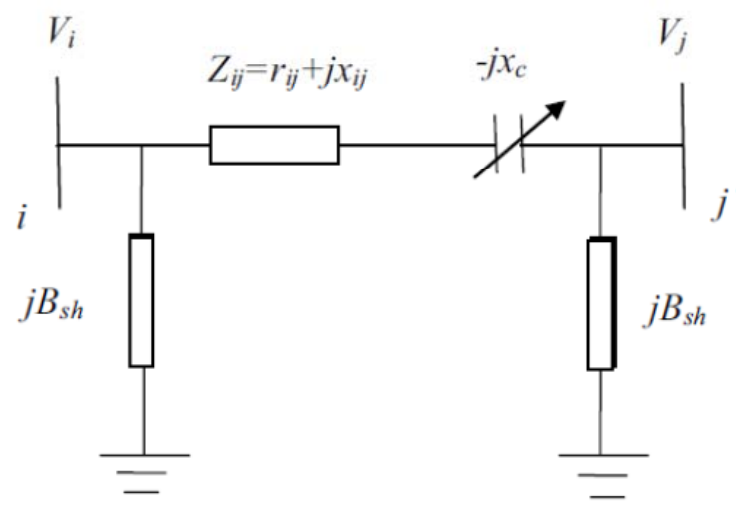

Figure 2. Static model of line with TCSC

Commonly, power injection model [8]-[13] is used for the static modelling of TCSC in power system. TCSC behaves as variable capacitive reactance. It reduces the line reactance during the operation which improves the power transfer capability. The injection model represents the TCSC as a device that injects certain amount of active and reactive power in a node.

$$
\begin{aligned}
& P_{i c}=V_{i}^{2} G_{i j}^{\prime}-V_{i} V_{j}\left[G_{i j}^{\prime} \operatorname{os}\left(\delta_{i j}\right)+B_{i j}^{\prime} \sin \left(\delta_{i j}\right)\right] \\
& \left.Q_{i c}=-V_{i}^{2}\left(B_{i j}^{\prime}+B_{s h}\right)-V_{i} V_{j}\left[G^{\prime}{ }_{i j} \sin \left(\delta_{i j}\right)-B_{i j}^{\prime} \cos \delta_{i j}\right)\right] \\
& P_{j c}=V_{j}^{2} G_{i j}^{\prime}-V_{i} V_{j}\left[G_{i j}^{\prime} \cos \left(\delta_{i j}\right)+B_{i j}^{\prime} \sin \left(\delta_{i j}\right)\right] \\
& \left.Q_{j c}=-V_{j}^{2}\left(B^{\prime}{ }_{i j}+B_{s h}\right)-V_{i} V_{j}\left[G_{i j}^{\prime} \sin \left(\delta_{i j}\right)-B^{\prime}{ }_{i j} \cos \delta_{i j}\right)\right]
\end{aligned}
$$

Where

$$
\begin{aligned}
& \mathrm{G}^{\prime}{ }_{\mathrm{ij}}=\mathrm{r}_{\mathrm{ij}} /\left[\mathrm{r}_{\mathrm{ij}}^{2}+\left(\mathrm{x}_{\mathrm{ij}}-\mathrm{x}_{\mathrm{c}}\right)^{2}\right] \\
& \mathrm{B}^{\prime}{ }_{\mathrm{ij}}=-\left(\mathrm{x}_{\mathrm{ij}}-\mathrm{x}_{\mathrm{c}}\right) /\left[\mathrm{r}_{\mathrm{ij}}{ }_{\mathrm{ij}}+\left(\mathrm{x}_{\mathrm{ij}}-\mathrm{x}_{\mathrm{c}}\right)^{2}\right]
\end{aligned}
$$

\section{CONGESTION MANAGEMENT}

In deregulated power industry one of the major issues is the transmission line congestion. At present in the world, electric utilities have been increased their generation to meet the increased demand for electric power. The network constraints include thermal limits, voltage/VAR requirements and the stability considerations. In uncontrolled electric system or in vertically integrated electric system, congestion cannot be tolerated except briefly. Because of this it may lead to the outages of the transmission lines with uncontrolled loss of load. The condition where overloads in transmission lines occur is called congestion. Congestion management in is not simple in the deregulated power environment. Flexible Alternative Transmission System (FACTS) devices can be an alternative to reduce the flows in heavily loaded lines, resulting in an increased loadability, low system loss, improved stability of the network and reduced cost of production by controlling the power in the network.

\section{PROBLEM FORMATION}

\subsection{Screening for contingency}

Without contingency there is no need for any compensation. In most of the operating conditions, an optimal placement of FACTS devices is one which gives the best results. The severe line outage contingency is found with Maximum Total Real Power Loss index (MPI) and is defined as

$$
\mathrm{MPI}=\max \left(\mathrm{P}_{\mathrm{L} 1}: \mathrm{P}_{\mathrm{Ln}}\right)
$$

Where $\mathrm{n}$ is the total number of lines. 


$$
\mathrm{P}_{\mathrm{L}}=\mathrm{P}_{\mathrm{G}}-\mathrm{P}_{\mathrm{D}}
$$

$\mathrm{P}_{\mathrm{G}}$ is power generation and $\mathrm{P}_{\mathrm{D}}$ is power demand. Depending on the total active power loss, the ranking of the critical lines were considered.

\subsection{Proposed index for optimal placement of TCSC}

Real and reactive power loss deviation based sensitivity index have been used in this work to optimally place TCSC to reduce the overflows in the transmission lines which results in an increased loadability of the power system and so the maximum relief of congestion management problem is achieved and also improves the voltage stability as well as security. Screening of the critical line outage is done with Maximum Real Power Loss index (MPI). The optimal location of TCSC has been decided by the Total Real and Reactive Power Loss Deviation Based Sensitivity indexes (PLDS and QLDS) with rank co-relation, computed for each transmission line is defined as follows (with suitable compensation i.e., 10\% to $70 \%$ ). Total Real Power Loss Sensitivity Index,

$$
\begin{aligned}
& \mathrm{PLDS}=\left(\mathrm{P}_{\mathrm{Lb}}-\mathrm{P}_{\mathrm{La}}\right) / \mathrm{P}_{\mathrm{La}} \\
& \mathrm{QLDS}=\left(\mathrm{Q}_{\mathrm{Lb}}-\mathrm{Q}_{\mathrm{La}}\right) / \mathrm{Q}_{\mathrm{La}}
\end{aligned}
$$

where

$\mathrm{P}_{\mathrm{La}}$ is real power loss after compensation.

$\mathrm{P}_{\mathrm{Lb}}$ is real power loss before compensation.

Ranking for the transmission lines is given according to PLDS index and QLDS index. So that means two different rankings were obtained. Now by using Rank Correlation concept a unique ranking is given for the transmission lines. So finally we identified the top ten transmission lines for the placement of TCSC.

\section{RANK CORRELATION}

Correlation is a statistical analysis which measures and analyses the degree or extent to which two variables fluctuate with reference to each other.

Pearman's rank correlation coefficient,

$$
\Gamma=1-\left(6 \sum \mathrm{D}^{2} /\left(\mathrm{N}^{3}-\mathrm{N}\right)\right)
$$

where

$\mathrm{D}^{2}$ is sum of the squares of the difference of two ranks.

$\mathrm{N}$ is number of paired observations.

From this rank correlation concept we can state that the PLDS index and QLDS index are fluctuate with reference to each other with $38.33 \%$ for our case study.

\section{SYSTEM STUDIES}

The proposed method for the optimal placement of TCSC has been tested on IEEE14 bus system. The IEEE14 bus system represents five generator buses and nine load buses. The top ten ranks for the critical lines are given on the severity of the total real power loss. It can be seen from Table 1 that the outage of line 3 in IEEE14 bus system is the most critical contingency.

Table 1. Line outage contingency ranking (base case loading)

\begin{tabular}{cccc}
\hline \multirow{2}{*}{ S.NO } & \multicolumn{3}{c}{ IEEE14 BUS SYSTEM } \\
& Line Outage & End Buses & Rank \\
\hline 1 & 3 & $2-3$ & 1 \\
2 & 2 & $1-5$ & 2 \\
3 & 13 & $6-13$ & 3 \\
4 & 4 & $2-4$ & 4 \\
5 & 1 & $1-2$ & 5 \\
6 & 7 & $4-5$ & 6 \\
7 & 15 & $7-9$ & 7 \\
8 & 5 & $2-5$ & 8 \\
9 & 17 & $9-14$ & 9 \\
10 & 10 & $5-6$ & 10 \\
\hline
\end{tabular}

IJECE Vol. 6, No. 5, October 2016 : 2041-2047 
Based on the PLDS index the top ten ranks for the transmission lines are shown in Table 2.

Table 2. Total Real Power Loss Deviation Sensitivity Index (PLDS)

\begin{tabular}{ccc}
\hline LINE & PLDS & RANK \\
\hline $2-4$ & 0.005757 & 1 \\
$2-5$ & 0.004072 & 2 \\
$1-2$ & 0.002949 & 3 \\
$1-5$ & 0.002808 & 4 \\
$3-4$ & 0.001966 & 5 \\
$5-6$ & 0.001545 & 6 \\
$4-5$ & 0.000281 & 7 \\
$6-12$ & 0.000281 & 8 \\
$13-14$ & 0.000281 & 9 \\
$6-11$ & 0.00014 & 10 \\
\hline
\end{tabular}

Based on the QLDS index the top ten ranks for the transmission lines are shown in Table 3.

Table 3. Total Real Power Loss Deviation Sensitivity Index (QLDS)

\begin{tabular}{ccc}
\hline LINE & QLDS & RANK \\
\hline $2-4$ & 0.046729 & 1 \\
$1-5$ & 0.036025 & 2 \\
$3-4$ & 0.03315 & 3 \\
$2-5$ & 0.027958 & 4 \\
$4-5$ & 0.010704 & 5 \\
$6-13$ & 0.004473 & 6 \\
$4-9$ & 0.003834 & 7 \\
$5-6$ & 0.003435 & 8 \\
$9-14$ & 0.002396 & 9 \\
$1-2$ & 0.002157 & 10 \\
\hline
\end{tabular}

According to rank correlation concept the two sensitivity factors are directly related with $55.6 \%$.

In the most congested line i.e line between bus 3 and bus 4, the loading has been increased to 5.01 times from the base state to fault state. After installing TCSC in line 9-10 on the basis of PLDS index, the loading of line $9-10$ increases to $1.07 \%$ in exchange for a loading decrement of line $10-11$ to $1.47 \%$ and loading of line $7-9$ is inceased to $0.078 \%$ and for line $4-9$ it is increased to $0.18 \%$. By most of the operational standards, the system with one huge violation is much more severe than that with many small violations. As it is seen in Table 4, the loading changes of other lines are negligible.

Table 4. Loading of the lines before and after placing TCSC

\begin{tabular}{ccc}
\hline Line & $\begin{array}{c}\text { Loading during fault } \\
\text { Without TCSC (MVA) }\end{array}$ & $\begin{array}{c}\text { Loading With } \\
\text { TCSC (MVA) }\end{array}$ \\
\hline $1-2$ & 31.193 & 31.194 \\
$1-5$ & 45.367 & 45.365 \\
$2-4$ & 60.856 & 60.860 \\
$2-5$ & 47.265 & 47.262 \\
$3-4$ & 50.553 & 50.555 \\
$4-5$ & 58.810 & 58.841 \\
$4-7$ & 7.722 & 7.723 \\
$4-9$ & 8.882 & 8.898 \\
$5-6$ & 28.028 & 27.991 \\
$6-11$ & 9.756 & 9.677 \\
$6-12$ & 9.112 & 9.116 \\
$6-13$ & 21.525 & 21.545 \\
$7-8$ & 38.503 & 38.511 \\
$7-9$ & 39.399 & 39.430 \\
$9-10$ & 6.831 & 6.904 \\
$9-14$ & 10.649 & 10.626 \\
$10-11$ & 5.281 & 5.207 \\
$12-13$ & 2.052 & 2.056 \\
$13-14$ & 7.009 & 7.033 \\
\hline
\end{tabular}


Bus voltage level before and after compensation process is shown in Table 5. In spite of effective relief of congestion, it is clear the improvement of voltage stability is negligible and there is impermissible voltage drop at some of the buses. Other results of load flow calculation before and after installing of TCSC are shown in Table 6.

Table 5. Voltage Level Before and After Compensation

\begin{tabular}{ccc}
\hline BUS & $\begin{array}{c}\text { Voltage in p.u } \\
\text { without TCSC }\end{array}$ & $\begin{array}{c}\text { Voltage in p.u with } \\
\text { TCSC }\end{array}$ \\
\hline 1 & 1.060 & 1.060 \\
2 & 1.045 & 1.045 \\
3 & 1.020 & 1.010 \\
4 & 1.031 & 1.025 \\
5 & 1.032 & 1.027 \\
6 & 1.070 & 1.070 \\
7 & 1.066 & 1.062 \\
8 & 1.090 & 1.090 \\
9 & 1.059 & 1.053 \\
10 & 1.054 & 1.048 \\
11 & 1.058 & 1.055 \\
12 & 1.055 & 1.054 \\
13 & 1.051 & 1.048 \\
14 & 1.038 & 1.031 \\
\hline
\end{tabular}

Table 6. Other results of load flow calculation before and after installing of TCSC

\begin{tabular}{lcc}
\hline \multicolumn{1}{c}{ Parameter } & Without TCSC & With TCSC \\
\hline Active Power Generation (MW) & 262.197 & 279.312 \\
Reactive Power Generation(MVAR) & 20.968 & 45.408 \\
Active Power Loss(MW) & 3.200 & 7.122 \\
Reactive Power loss(MVAR) & -33.529 & -12.522 \\
\% Real Power loss & $1.22 \%$ & $2.55 \%$ \\
\hline
\end{tabular}

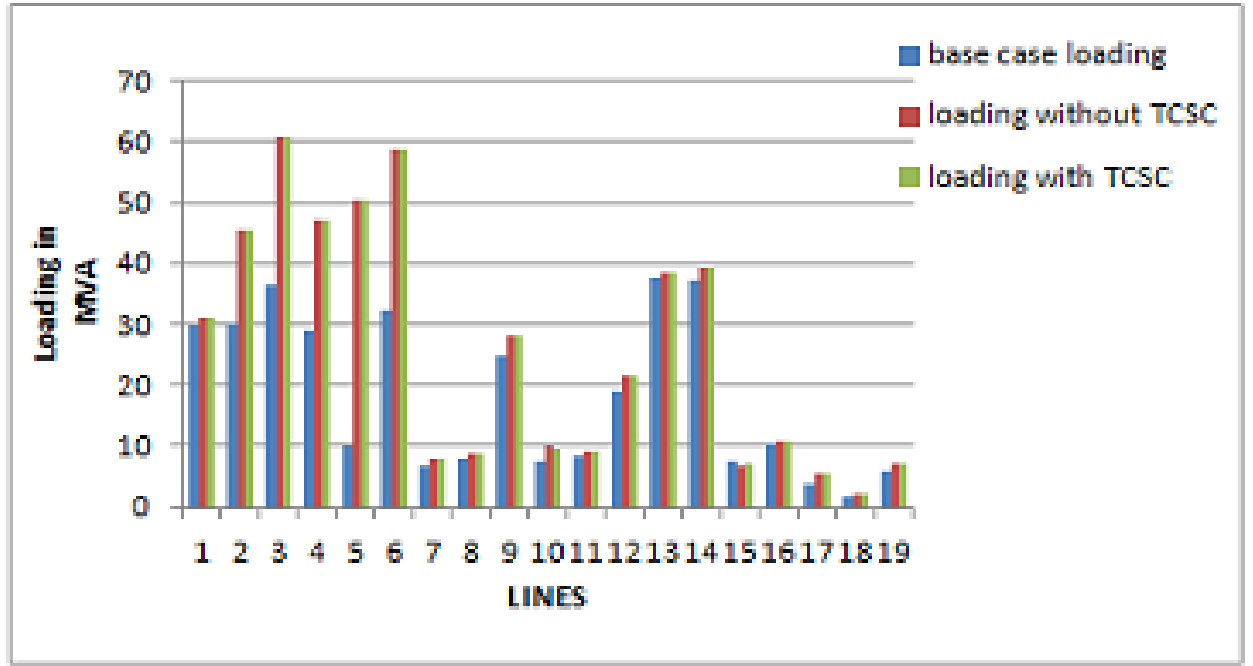

Figure 3. Loading Profile Before and After Compensation

\section{CONCLUSION}

In this paper a new method has been proposed to locate TCSC in power systems. The suggested approach is composed of sensitivity analysis and rank correlation concept. Every human beeing is good as well as bad. Depending on the situation they will behave. Similarly according to the power system operating conditions, the best location will be chosen based on PLDS and QLDS indexes. The result of load flow calculation before and after compensation process shows reduction of loading in congested lines. 


\section{REFERENCES}

[1] Y. Song and X. Wang, "Operation of Market-Oriented Power Systems," London, UK, Springer, 2003.

[2] N. Hingorani, "Flexible AC transmission," IEEE Spectrum, vol/issue: 30(4), pp. 40-45, 1993.

[3] CIGRE Working Group 14, 18, "Thyristor controlled series compensation," CIGRE Technical Broucher, vol. 112, 1996.

[4] J. Urbanek, et al., "Thyristor controlled series compensation prototype installation in the Slatt 500kv Substation," IEEE Trans.on Power Delivery, vol/issue: 8(3), pp. 1460-1469, 1993.

[5] L. Rajalakshmi, et al., "Congestion Management in Deregulated Power System by Locating Series FACTS Devices," International Journal of Computer Applications (0975 - 8887), vol/issue: 13(8), 2011.

[6] N. G. Higorani and L. Gyugyi, "Understanding FACTS Concept and technology of Flexible AC Transmission Systems."

[7] D. Murali, et al., "Comparison of FACTS Devices for Power System Stability Enhancement," International Journal of Computer Applications (0975 - 8887), vol/issue: 8(4), 2010.

[8] S. N. Singh and A. K. David, "Optimal Location of FACTS Devices for Congestion Management," Elect. Power Syst. Res., vol/issue: 58(2), pp. 71-79, 2001.

[9] S. N. Singh and A. K. David, "Placement of FACTS Devices in Open Power Market," Int.Conf. on Advances in Power System Control, Operation and Management, Hong Kong, pp. 173-177, 2000.

[10] H. Besharat and S. A. Taher, "Congestion Management by Determining Optimal Location of TCSC in Deregulated Power Systems," Elect. Power and Energy Syst., vol/issue: 30(10), pp. 563-568, 2008.

[11] A. S. Nayak and M. A. Pai, "Congestion Management in Restructured Power Systems Using an Optimal Power Flow Framework,” MS Thesis, Univ. Illinois Urbana- Champaign, pp. 30-44, 2002.

[12] N. Acharya and N. Mithulananthan, "Locating Series FACTS Devices for Congestion Management in Deregulated Electricity Markets," Elect. Power Syst. Res., vol/issue: 77(3- 4), pp. 352-360, 2007.

[13] N. Acharya and N. Mithulananthan, "Influence of TCSC on Congestion and Spot Price in Electricity Market with Bilateral Contract,” Elect. Power Syst. Res., vol/issue: 77(8), pp. 1010-1018, 2007.

\section{BIOGRAPHIES OF AUTHORS}

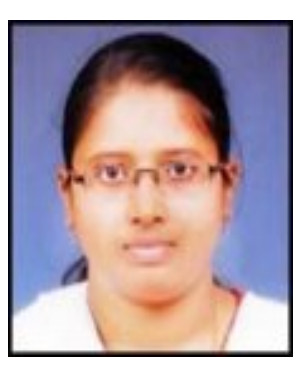

Naga Raja Kumari.CH is a Ph.D. Candidate in the Department of Electrical \& Electronics Engineering at the University of Acharya Nagarjuna at Guntur (India). She has received her M. Tech in Power System Engineering from the Acharya Nagarjuna University at Guntur and B. Tech in Electrical \& Electronics Engineering from Acharya Nagarjuna University, Guntur. Her research interest includes power systems operational and control, application of FACTS in deregulated power systems, and voltage stability and Power Quality. She is a life member of ISTE.

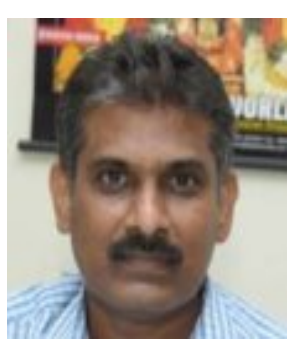

K. Chandra Sekhar is Professor \& Head of the department of Electrical \& Electronics Engineering in RVR \& JC College of Engineering, Guntur. He holds B.Tech in Electrical \& Electronics Engineering from Nagarjuna University, Guntur in the year 1991. M.Tech in Electrical Machines \& Industrial Drives from Regional Engineering College (REC), Warangal in the Year 1994 and Ph.D in the Faculty of Electrical Engineering, J.N.T U, Hyderabad in He has published numerous articles on Power Electronics \& Drives, FACTS Controllers, and Power Quality Improvement concepts. He is a member of IEEE, IETE, ISTE, IE (India) and Chartered Engineer (India). 